NORA RABOTNIKOF

\title{
Desencanto e individualismo
}

MI As allá de sus raíces etimológicas, desencanto es una A veces se constata la presencia de una "época de desencanto", como si se tratara de una configuración cultural nueva, sin recordar que algunos de los rasgos que comúnmente se asocian con ella ya estuvieron parcial o totalmente presentes en otras épocas (si el pensamiento occidental recordara cuántas veces en su historia creyó cortar amarras con una visión mágica o teológica del mundo, al menos en este aspecto, cada nueva generación desencantada no viviría tan perplejamente su descubrimiento). Otras veces, el desencanto se asocia más pedestremente con la desilusión, el desengaño, el fracaso o la traición de una promesa creída y defendida, y se traduce en una cruzada militante contra las viejas certezas, ante el temor de que los antiguos demonios resuciten. A veces, la crisis de las viejas utopías remata en una desconfianza visceral ante cualquier utopía. Finalmente, el desencanto se asocia en ocasiones simplemente a la madurez: "¿qué es aprender? Es desengañarse" diría Bernard Shaw.

Si los sesenta y los setenta fueron los años de "la gran promesa" para más de una generación ( $\mathrm{y}$ en ese sentido valdría la pena recordar que "en la medida en que se hace de la propia experiencia la piedra de toque para hallar significados comunes, el concepto de generación es el centro distintivo de la edad moderna..." $)^{1}$ desde mediados de los setenta entramos en el desencanto.

Este se manifiesta cada vez más como secularización de la política, como desencantamiento. El sentido de ruptura con la visión mágica del mundo, con el Providencialismo se

1 Bell, Daniel, Las contradicciones culturales del capitalismo, Alianza, Madrid, 1976, p. 95 
resume en la consigna, ya no sólo weberiana, de "sin dioses ni profetas, ni tampoco garantías". La política vuelve a ser actividad humana, demasiado humana, y ni la ciencia, ni la religión, ni el Espíritu pueden volver a otorgar sentido a la historia, desde la creación hasta la resurrección de los muertos. Los manuales de filosofía nos enseñan que la ubicación de la política en el campo de lo profano lleva ya bastantes siglos. Sin embargo, cada nueva generación parece necesitar hacer su propia experiencia.

A este rasgo saludable del desencanto como "desencantamiento del mundo" se une otro que parece tener raíces diferentes. Me refiero al deterioro real de algo que, a falta de un término mejor, llamaría identidades colectivas. Raíces diferentes porque si bien este deterioro tiene que ver con la crítica de ciertos mitos derivados de la visión providencialista de la historia (el tema del partido como "voluntad colectiva", y en general de toda "totalidad orgánica que representaba mágicamente a los individuos") también tiene un origen más terrenal en la destrucción, violenta en muchos casos, por extinción en otros, de ciertas solidaridades y lazos colectivos (reales o figurados). Esta crisis de identidades colectivas no se asocia entonces sólo con una revisión teórico conceptual sino también con la ruptura material o fracaso de ciertos proyectos de transformación, a lo que deberíamos agregar, en situaciones autoritarias, el tema ya estudiado de la "resocialización" vía mercado operada como contrapartida de la destrucción de organizaciones, y las medidas de disciplinamiento individualizante en general.

De estos dos rasgos del desencanto actual parecen derivar otras dos características relativamente nuevas. Por un lado, de la crítica al mito y la utopía, y de la pérdida de garantías trascendentes, surge una nueva apelación al realismo político. En algunos casos es la vuelta a aquella ética de la responsabilidad, que evalúa consecuencias y paradojas éticas frente a la ética de la convicción entendida como principismo abstracto. En otros casos, la apelación al realismo político pasa por alto o zanja demasiado fácilmente la cuestión de las múltiples alternativas a una misma situación, evitando el tema de la decisión y la responsabilidad. La apelación a "la realidad" y a la falta de alternativas puede ocupar el lugar de aquella otra "necesidad histórica" que se quiere desterrar. El llamado realismo político se identifica también a veces con la aceptación resignada de algún grado de violencia contra las propias convicciones. Pero más que la apela- 
ción al realismo político, interesa por nuestro tema el otro rasgo emergente: la reafirmación del individuo.

Aclaremos, el desencanto no es privativo del pensamiento "de izquierda". Al fin y al cabo, la izquierda no fue la única generadora de utopías. Es cierto que dentro de esta tradición el desencanto, con los rasgos que hemos señalado, adquiere a veces características más notorias. Alguien podría decir que se trata de un fenómeno de proporcionalidad entre acción y reacción (cuanto mayor fue la magia más violento el reconocimiento del sinsentido), pero, como sabemos, el tema del desencanto parece cuestionar una vez más la distinción jacobina entre izquierda y derecha. Sin embargo, en relación al tema del redescubrimiento del individuo, el pensamiento de izquierda parece presentar un rasgo novedoso en relación a la afirmación, un tanto tardía, de los ámbitos subjetivos, excluídos antes del campo de lo político. Paradójicamente, mientras se asiste a este redescubrimiento del individuo por parte de una tradición que históricamente había acentuado las identidades colectivas, la sociedad o las fuerzas objetivas, parte del liberalismo, sin negar el papel central del individuo vuelve sobre antiguos temas tales como el sentimiento comunitario, el refreno $\mathrm{a}$ las apetencias individuales en función de valores superiores, e $\ldots$ y afirma abiertamente sus sospechas frente a las posibilidades destrultivas de este individuo, unidad central de su teoría.

¿En qué sentido este nuevo individualismo es un descubrimiento del desencanto? Dejo de lado la revaloración de los derechos y garantías individuales, surgida a partir del debate en torno a la superación de la alternativa "democracia formaldemocracia real" de los años recientes. En todo caso el resultado de este debate dejó definitivamente atrás cierto desprecio por la defensa de los derechos individuales, por el derecho al disenso y al pluralismo y por las garantías constitucionales, que de meros espacios tácticos se transformaron en valores a defender o a conquistar, afirmándose así la materialidad real de lo que hasta entonces era considerado puramente formal.

En realidad este redescubrimiento del individuo tiene que ver con la eclosión de la subjetividad, en la que se descubren aspectos puestos antes en un cono de sombra por la dilusión en lo colectivo (lucha de masas, partido, prioridad orgánica). Por supuesto, para hablar de descubrimiento o redescubrimiento del individuo suponemos que hubo antes algún tipo de dilusión, superación o integración de ese individuo o en una instancia más 
comprensiva o amplia, en un "nosotros" o un "todos" que alternativamente daba sentido u oscurecía a ese yo. Hegelianamente, en una especie de eticidad griega aún no mediada por la fisura del cristianismo. Hábía quienes pues, como Monsieur Jourdain, eran hegelianos sin saberlo.

Esta inclusión del individuo en una identidad colectiva fuerte no siempre fue vivida como sacrificio. Por el contrario, es posible que en los momentos en que ese "nosotros" se anteponía, la opción entre individuo y comunidad u organización no fuera vivida propiamente como tal, ni como obediencia a una coacción externa ni tampoco como resultado de una deliberación racional. Se trataba en cambio de una "orientación de sentido" donde la dimensión individual no aparecía. La política como lo público, opuesto a lo individual privado, subordinado permanentemente, aparece por ejemplo en la conciencia desgarrada de una vida individual ofrendada en una gimnasia sin objetivo del personaje de "La guerra ha terminado", o en los sacrificios al stalinismo de Federico Sánchez, hasta la tiranía del colectivo que aplasta incluso la capacidad de reír en un Kundera.

En esta tradición de pensamiento, parecía recuperarse aquella concepción imputada a la antigüedad, según la cual lo privado era la esfera de la indigencia, contraria a la esfera política o pública, ámbito de la libertad. No en vano el têma de la redefinición de lo público y lo privado ocupó gran parte de la discusión política de los últimos años. En ese sentido se produjo una revalorización de la esfera privada individual que ya no es pensada como esfera de la privación sino como ámbito inalienable de la libertad.

Así, parece asistirse a una recuperación del alejamiento de lo público político y a una reprivatización. Lo privado individual en lugar de ser considerado negativamente es visto nuevamente, como diría Constant, como "el lugar de todos los placeres". Pero por otro lado, en un movimiento aparentemente paradójico se reconoce una "repolitización" (no en sentido partidario) de temas antes considerados no políticos: familia, sexualidad, vida cotidiana, que aparecen precisamente como las esferas de construcción de esa libertad. Lo personal y lo intersubjetivo buscan expresión en los llamados "ámbitos micro", que reivindican su autonomía frente a organizaciones totalizadoras, partido o estado, creaciones que junto con los dioses, los profetas y las garantías, parecen formar parte de la etapa teológica.

Aparecen así doś figuras: el individuo insumiso, que, no 
pudiendo adherir ya a utopías sustantivas exalta la insumisión como consigna, y el individuo ciudadano, que toma la terrible decisión de ser razonable, para construir las reglas procesales de convivencia pacífica.

En el primer caso, el desencanto ha minado la posibilidad de construir utopías sustantivas. No se trata entonces de elaborar nuevas teodiceas ya que al fin y al cabo ninguna de ellas puede resistir el peligro de la desilusión. Recuperando una actitud libertaria, se trata de encontrar un proyecto, como dice Savater, "que no exija fe y por lo tanto tampoco acatamiento". Preservar entonces la posibilidad de rebeldía individual construyendo una idea ética de revolución que "permita no creer en nada pero obligue a hacer algo, a seguir practicando una $u$ otra forma de insumisión, a diferencia de otras concepciones políticas que obligan a creer en algo y dispensan de cualquier gesto que no sea el mero acatamiento". ${ }^{2}$ Frente a la utopía y a las falsas identidades, se trata de liberar del todo a esta individualidad de su cárcel institucional, exaltando la des-construcción de lo que quede construído, el des-orden, la dis-continuidad. En esta posición, la exaltación del individuo apunta a un horizonte de extinción de la política, entendida ésta como relaciones de poder y dominación.

Frente a esta posición del individuo insumiso cabria preguntarse si ese culto a la trasgresión permanente podría sustituir o suplir esa unidad que las instituciones no logran, si podría crear espacios nuevos o códigos culturales que permitan la afirmación de la vida colectiva. Después de todo la problemática del "orden" no es sólo afirmación conservadora o totalidad, es también necesidad de construcción de continuidad en el tiempo y en el espacio. Extinción de la política como ejercicio del poder, horizonte último, pero ¿también extinción de aquello que Edelman llamara la política como ritual, como construcción simbólica?

individuo razonable. Es justamente la vieja cuestión del orden justo, de la vida en comunidad a partir de cada cual, con lo negociable y lo irrenunciable: el replanteo de una vieja obsesión. En lugar de estar concentrada en una organización que impone por la fuerza su voluntad, la política vuelve a ser pensada como acuerdo racional entre individuos. Principios profanos de una ética universalista que se rescatan como punto de partida de un

\footnotetext{
${ }^{2}$ Șavater, Fernande, fl mito del héroe, Taurus, Madrid, p. 43
} 
acuerdo en torno a procedimientos que permitan, la universalización en ciertos casos, el çompromiso en otros. Recuperación del proyecto de las Luces, que en muchos casos se percibe no sólo como posibilidad inconclusa sino como descubrimiento novedoso a tres siglos de distancia. En este caso como decimos se afirma la materialidad, el carácter constituyente de lo formal. Pero también aquí habría que preguntarse si esas formas que organizan conductas no apuntan acaso a referencias comunes, a identidades que no se agotan en el concepto de ciudadanía.

Pero, curiosamente, también el viejo liberalismo se aterra ante los desvaríos del individuo insumiso al tiempo que parece percibir los límites del individuo razonable. Si el socialismo redescubre temas liberales, los liberales se acercan a su adversario de antaño, y los temas y argumentos tradicionalmente conservadores adquieren una luz diferente articulados con el desencanto ante su propio proyecto.

Para ilustrar este otro tipo de desencanto elijo a Daniel Bell porque, más allá de las autodefiniciones (..."fui un menchevique toda la vida, alguien que escoge, casi siempre, el mal menor") $)^{3}$, es básicamente un liberal desencantado que, sin embargo, no ha renunciado del todo a ciertos principios básicos.

Alguien ha dicho que el neoconservadurismo es la red en la que saltan los liberales cuando se asustan de su propio liberalismo. ¿Qué le asusta a Bell? Aparentemente, la vorágine desatada por ese individuo lanzado frenéticamente hacia la afirmación de sí mismo. Es este individuo insumiso y anarquizante, hijo de la sociedad burguesa quien termina en el matricidio, liquidando todo lo liquidable y vaciando de horizonte al propio nihilismo. "El problema de la modernidad es el de la creencia, para usar un término anticuado es una crisis espiritual, pues los nuevos asideros han demostrado ser ilusorios y los viejos han quedado sumergidos. Es una situación que nos lleva de nuevo al nihilismo, a falta de un pasado o de un futuro, sólo hay un vacío". "Pero, como decíamos, ni siquiera el nihilismo es una alternativa: "El nihilismo fue antaño una filosofía temeraria, cuando había algo que destruir y algo que poner en su lugar. Pero hoy ¿qué queda por destruir el pasado y quién tiene esperanzas en el futuro?". 5

Más allá de si Bell confunde causas y consecuencias, más

${ }^{3}$ Bell, Daniel "El gran inquisidor y Lukacs", Revista Nexos. n., 1982.

${ }^{4}$ Bell, Daniel, Las contradicciones.... p. 120

5 Ibid. 
allá de la posible sobredimensión otorgada al tema de la modernidad estética, lo interesante es que Bell en ningún momento cree confirmar viejas desconfianzas frente a la ilustración (como en el caso de los neoconservadores alemanes) ni tampoco parece abjurar, en el plano teórico, de su arraigado liberalismo.

En esta visión, la sociedad burguesa ha tenido una doble fuente y un doble destino. Una de sus fuentes fue aquella ética protestante que diera paso al ethos del capitalismo como autocontrol, compulsión al trabajo y al ahorro y temor a Dios. La otra fue el individualismo radical, la apetencia desenfrenada, el hobbesianismo secular controlado en política por el soberano pero ilimitado en lo económico y lo cúltural. Pero esta segunda fuente no es considerada por Bell (y en ello radica la no autenticidad de su conservadurismo) como un principio de perversión. La extensión universal del derecho, la idea profana de justicia, las ideas de libertad y de igualdad derivan de esta secularización de la ética protestante y también de este individuo insaciable. El problema es que, siguiendo a Weber, el estuche ha quedado vacío. Cada una de las esferas: economía, política, estética, etc., ha adquirido una aceleración propia y una estructuración a partir de ejes axiales contradictorios. El espíritu ascético de autocontrol dio lugar a la racionalidad formal instrumental de la estructura técnico-económica, pero ya no hay principios culturales que constituyan el espíritu de ese funcionamiento. Esta ya no concuerda ni con el hedonismo fácil de la sociedad de coṇsumo, ni con una autoconciencia cultural que exalta la sinrazón y la exasperación del yo individual. El orden político carece de fuerza cultural capaz de sofrenar los intereses individuales en función del bien colectivo o de principios vinculantes generales. La racionalización económica y política no basta para autosustentarse ni para enfrentar una cultura en la que el individuo, con sus humores apocalípticos, parece exaltar una y otra vez, al abismo.

Tal es el diagnóstico desde la óptica de Bell. La posibilidad de una nueva cultura, como se sabe, pasa en esta propuesta por la recuperación del asidero permanente de los tiempos de crisis: la religión. Extraña culminación del desencanto. Pero, una vez más, la salida no es fácil. Bell no es un Solyenitzin como para afirmar que Occidente ha olvidado la herencia del milenio anterior, o como para recordar que los derechos humanos tenían su base en dios y que tenemos que salir de la senda del pecado de humanismo en la que hemos caído, por lo menos desde el Renacimiento. Para Bell no se trata de desempolvar los viejos 
valores de la obediencia, la tradición, la sumisión ni tampoco esta vuelta a la religión tiene el sentido de un retorno a lo sagrado. Por un lado, aparece como respuesta en el plano metafísico al viejo problema del sentido del mundo. Por otro, como una referencia cultural común, capaz de orientar o por lo menos de no desquiciar la conducta política y económica de los individuos.

Un lugar para el individuo, un fundamento para el sentido comunitario, un puente para la continuidad con el pasado y el porvenir, tal parece ser la funcionalidad de la religión en un mundo donde, ni la abundancia económica, ni la eficiencia técnica ni el sistema político, pensado como hogar público, pueden ofrecer sentido de pertenencia o de continuidad a ese individuo. Individuo que, por otra prte, sigue siendo pensado y afirmado como sujeto de la política y de la sociedad.

Desde esta perspectiva, la religión aparece entonces después de la ciencia, de la política, de la estética, de la moral laicizada como "la búsqueda cognoscitiva del esquema de orden general de la existencia, de la necesidad efectiva de establecer rituales y hacer sagradas esas concepciones, de la necesidad primordial de relacionarse con algunos otros o con un conjunto de significados que establezcan una respuesta trascendente al yo, y de la necesidad existencial de afrontar la irrevocabilidad del sufrimiento y la muerte". 6

Con todo, hay algo que no termina de convencer al propio Bell y que nos habla de algo forzado en este conservadurismo y de algo demasiado reciente en esta conversión a la religión. Hay problemas que ni la sensibilidad del liberal ni la mirada del sociólogo pueden soslayar. Finalmente, la religión, la tradición, la vuelta al pasado no resuelven del todo su problema: "Las respuestas que busca un temperamento liberal son éticas. La dificultad es que la adhesión a una ética disuelve lo particular en lo universal... Dado lo que sabemos sobre la naturaleza del hombre, el sueño de la Ilustración de hacer de la humanidad una es fútil... Pero si ser sólo cosmopolita es carecer de raíces, ser solamente parroquial es ser sectario y perder los vínculos con otros hombres, otros conocimientos, otra fe".

No son estrictamente los contenidos de la ética puritana los que habría que rescatar desde esta óptica. A Bell no se le escapa (como tampoco a Marcuse) que ellos serían hoy contra-

${ }^{6}$ Ibid. p. 163 
dictorios con la civilización de la tarjeta de crédito. ¿Hay algo - que más que terror conservador ante el caos y el desorden en este tardío descubrimiento de la religión? ¿Por qué la creencia y la justificación no podrían construirse nuevamente a partir de la cultura política y no de la religión? Si al comienzo estuvo la promesa originaria de la tierra de promisión y el respeto al orden político concebido como sistema abierto, igualitario, sensible a los individuos de distintos orígenes que buscaban su incorporación y respetaban los principios de la constitución, ¿por qué volver entonces a la religión, y no buscar vías políticas, nuevas formas de participación, nuevas temáticas, ese sentido perdido?

Para Bell, si bien es necesaria una filosofía pública, un nuevo contrato social, la definición del "hogar público", en el fondo ello no es suficiente. Para el liberal desencantado, este hogar público, sede de la discusión y ejecución de la justicia distributiva, espacio de intersección entre recursos y prioridades politicas, lugar de concertación parece no poder generar por sí mismo ni la responsabilidad de las partes, ni la moderación de las demandas, ni el compromiso de cumplir con las reglas. El acuerdo racional debe recuperar la historia: "un pacto social que, si bien renegociado en el presente renovable, no ignore ni pueda ignorar el pasado". La advertencia conservadora resuena: "La hybris del liberalismo clásico y también el utopismo socialista fue creer que cada nueva generación y con un nuevo contrato social, los hombres podían comenzar de nuevo, descartar el pasado y recrear las instituciones". Historicismo e Ilustración convergen finalmente en una salida que no convence a nadie. Para los conservadores, resulta demasiado liberal en esta afirmación de la democracia como conjunto de procedimientos formales irrenunciables. Para los liberales, demasiado conservador en esta desconfianza o en este reconocimiento de los límites histórico-culturales del contrato.

Si algo de cierto hay en este movimiento dibujado por el cual la izquierda asume el liberalismo político y los liberales (o algunos liberales) descubren la insuficiencia de las formas políticas tradicionales recayendo en temas orgánico-comunitarios ¿qué conclusiones provisionales podríamos extraer de este periplo?

En primer lugar, y casi como elemento de buen sentido, reconocer que puede resultar tramposo comparar a un liberal norteamericano, emergente de la llamada sociedad postindustrial, a su crítica a las formas políticas tradicionales y los 
mecanismos de la democracia representativa, con una "izquierda en general". Podría entenderse que hay una especie de adelanto de uno respecto a los otros, en tanto éstos redescubren desencantadamente las ventajas de la democracia representativa, del parlamentarismo, de la esfera privada y de la figura del individuo, mientras el otro, sobre una base liberal, busca salvar estos principios volviendo a la religión. Como sí en el primer caso se estuviera descubriendo el proceso "antes" de su punto de inflexión y en el segundo "después". Frente a esta intepretación, tendríamos que aclarar que no nos parece válido afirmar que la democracia representativa, la defensa de los derechos individuales, el poder de una opinión pública formada, la posibilidad de reglas formales aceptadas por todos sean formas insuficientes o engañosas sobre todo en aquellas sociedades donde éstas no existen o no han existido nunca. No se trata, entonces, de criticar a unos desde la madurez de los otros.

Sin embargo, y en un punto más específico, la apelación a la cultura (no necesariamente a la religión) parece poner otra vez sobre el tapete la función del mito, del ritual a través del cual los hombres dan sentido a su vida social y se reactualiza o se construye un sentimiento de colectividad. Las "formas" constituyen, además de reglas intersubjetivamente aceptadas, sistemas de reconocimiento recíproco entre los sujetos. Si en un caso, se redescubre la centralidad de las formas políticas en el otro se intenta ir más allá de las formas políticas tradicionales, quizá para salvar un déficit que el sistema político no puede resolver por sí mismo.

Si las expresiones ligadas a la subjetividad individual son pensadas sólo desde la exaltación del individuo o (como hace Bell) desde la desconfianza y el temor ante el individuo insumiso, entonces la problemática del orden es sólo una preocupación autoritaria. Y si, inversamente, esa subjetividad sólo puede ser pensada como privacidad volvemos a Constant y a la libertad de los modernos, a aquellos que sólo se interesan superficialmente por la vida pública y entonces, como Bell, habrá que buscar el remedio al malestar a través de otras terapias.

Si es posible, por el contrario, que esas identidades colectivas, fundadas en experiencias comunes, en situaciones de vida pueden adquirir expresión política de otra manera, sin estar condenadas a ser eclosiones sólo marginales, será posible encontrar un punto entre la magnífica totalidad homogeneizada y este individuo, el insumiso, el privado, o el simple votante. 
$\mathrm{Si}$ es posible, entonces, pensar esos reconocimientos, esos rituales y símbolos como identidades colectivas, lábiles, precarias, parciales y plurales que no reivindiquen para sí las pretensiones de un Gran Proyecto, pero que creen formas de reconocimiento y participación (la dimensión participativa no es siempre y necesariamente contradictoria con la eficacia como lo pensaba Weber), entonces la política, concebida no sólo como poder y dominación sino como orden de la unidad y la diversidad, podrá incorporar a esa individualidad, ahora sí en una visión auténticamente desencantada y por lo tanto responsable. 